\title{
The Efficacy and Safety of YAG Laser Vitreolysis for Symptomatic Vitreous Floaters of Complete PVD or Non-PVD
}

\author{
Tiezhu Lin · Tongtong Li $\cdot$ Xinmei Zhang Yannian Hui · \\ Salissou Moutari · Emmanuel Eric Pazo · Guangzheng Dai · \\ Lijun Shen
}

Received: August 9, 2021 / Accepted: November 1, 2021 / Published online: November 15, 2021

(C) The Author(s) 2021

\section{ABSTRACT}

Introduction: To evaluate and compare the efficacy and safety of YAG laser vitreolysis in treating symptomatic vitreous floaters of complete posterior vitreous detachment (PVD) and non-PVD.

Methods: In this prospective cohort study, 51 eyes with symptomatic floaters were treated with YAG laser vitreolysis. Participants were divided into complete PVD and non-PVD groups. Objective visual quality measures including the Strehl ratio (SR), internal

Supplementary Information The online version contains supplementary material available at https:// doi.org/10.1007/s40123-021-00422-6.

T. Lin · L. Shen $(\bowtie)$

Eye Hospital and School of Ophthalmology and Optometry, Wenzhou Medical University,

Wenzhou, Zhejiang, China

e-mail:slj@mail.eye.ac.cn

T. Lin · T. Li · X. Zhang · E. E. Pazo · G. Dai

He Eye Specialist Hospital, Shenyang, Liaoning, China

Y. Hui

Eye Institute of Chinese PLA, Department of Ophthalmology, Xijing Hospital, Air Force Medical University, Xi'an, Shanxi, China

S. Moutari

School of Mathematics and Physics, Queens

University Belfast, University Road, Belfast BT7

$1 \mathrm{NN}$, Northern Ireland, UK spherical aberration (SA), internal comatic aberration (CA), internal high-order aberration (HOA), area ratio of modulation transfer function (MTFa) and Vitreous Floaters Symptom Questionnaire (VFSQ-13) scores were used to compare the efficacy of YAG laser vitreolysis treatment between two groups.

Results: The mean age of all patients was $56.80 \pm 10.82$ years old. In total, 36 of 51 (70.59\%; 95\% CI 58.10-83.10) patients reported their symptoms as significant or complete improvement after YAG laser vitreolysis treatment. Post-treatment MTFa, internal SA and internal HOA were significantly better compared to baseline $(26.19 \pm 14.73$ vs. $29.19 \pm 17.98, \quad p=0.013 ; \quad 0.05 \pm 0.05 \quad$ vs. $0.04 \pm 0.04, p=0.031$ and $0.23 \pm 0.22$ vs. $0.16 \pm 0.07, p=0.044$; respectively) in all eyes. Twenty-nine of 51 (56.86\%) eyes had floaters of non-PVD type. Significant or complete subjective improvements in the PVD group and nonPVD group were $72.73 \%$ and $68.97 \%$ $(p=0.344)$, respectively.

Conclusions: Improved subjective and objective visual quality in participants with symptomatic floaters following YAG laser vitreolysis was found in both groups. The efficacy of YAG laser vitreolysis was comparable in floaters of complete PVD and non-PVD types.

Keywords: Floaters; Posterior vitreous detachment; Vitreolysis; Weiss ring; YAG laser 


\section{Key Summary Points}

Why carry out this study?

Primary symptomatic floaters are common in adults. Some patients feel that floaters have a significant impact on the quality of life and seek treatment. YAG laser vitreolysis has good safety and cost performance, but previous studies have mostly focused on the floaters of complete posterior vitreous detachment (PVD) type. This study is the first to compare the outcomes of floaters of complete PVD type to non-PVD type in patients undergoing YAG laser vitreolysis.

What was learned from the study?

Our results demonstrate that the efficacy of YAG laser vitreolysis is comparable in floaters of complete PVD type and non-PVD type. Scanning laser ophthalmoscope is an effective device for examining vitreous floaters, but its sensitivity is lower in the non-PVD type than in the complete PVD type. The values of objective visual quality measures such as area ratio of modulation transfer function (MTFa), internal spherical aberration (SA) and internal high-order aberration (HOA) in eyes with symptomatic floaters could be improved after YAG laser vitreolysis therapy.

\section{INTRODUCTION}

Primary symptomatic floaters are a common ocular condition in adults. Even in a younger population, the prevalence of floaters was reported to be close to 76\% [1]. Primary vitreous floaters are due to localized build-ups caused by the molecular derangement of vitreous collagen fibrils during the degenerative process [2]. These artifacts within the eye can lead to visual symptoms such as cobwebs, spots, shadows and other assorted shapes that appear to drift across the visual field with the movement of the eyes [3, 4].
Most patients with floaters get used to this condition and possibly neuroadapt to it. Visual symptoms due to floaters can also diminish when the vitreous opacities move anteriorly and out of the visual axis $[5,6]$. However, a small group of patients feel that floaters have a significant impact on the quality of life and seek treatment [7-9]. Pars plana vitrectomy [5, 10-12] or YAG (yttrium-aluminum garnet) laser vitreolysis [13] are primary treatment options in published literature, and these treatment methods have their own advantages and disadvantages. While vitrectomy has been documented in reducing the symptoms of floaters and is considered to be an effective option, it may lead to more side effects compared to laser therapy [14, 15]. In 17,615 eyes undergoing vitrectomy for vitreous opacities in the Intelligent Research in Sight Registry, $12.4 \%$ eyes returned to the operating room for cataract surgery, and $3.7 \%$ eyes returned to the operating room for a non-cataract procedure within 1 year [16]. Laser treatment has good safety and cost performance, but previous studies have mostly focused on the floaters of complete PVD type [17-19], and various publications have questioned its effectiveness [20].

The present study was undertaken to evaluate and compare the subjective and objective efficacy of YAG laser vitreolysis for two types of primary symptomatic floaters (complete PVD type and non-PVD type) by comparing changes in questionnaire scores and objective visual quality measures before and after treatment.

\section{METHODS}

\section{Participants}

This single-center prospective study included 51 eyes of 51 patients ( 37 women and 14 men) at He Eye Specialist Hospital from February 1, 2020, to July 30, 2020. All patients were experiencing symptomatic floaters and had a strong desire for remedial treatment. This study was performed under institutional review board approval and conformed to the tenets of Declaration of Helsinki (YJ [2020] K001.01). All participants were informed of their rights and 
provided written informed consent before undergoing study procedures. Slit-lamp examination, Snellen best corrected visual acuity (BCVA), intraocular pressure (IOP), spherical equivalent (SE), vitreous and fundus examination through dilated pupil, ultrasound B scan and scanning laser ophthalmoscope (SLO, Optos ${ }^{\circledR} 200 \mathrm{Tx}$, Optos ${ }^{\circledR}$, Dunfermline, UK) were performed on the patients (Fig. 1). The objective visual quality measures were assessed by corneal tomography and wave front aberration measurement systems (OPD-Scan III, Nidek Inc., Tokyo, Japan). The main measures of objective visual quality were as follows: the Strehl ratio (SR), internal spherical aberration (SA), internal comatic aberration (CA), internal high order

\begin{tabular}{|c|c|c|c|c|c|}
\hline 1. & $\begin{array}{l}\text { You noticed floaters when looking at the blue } \\
\text { sky. }\end{array}$ & 1 & 2 & 3 & 4 \\
\hline 2. & $\begin{array}{l}\text { You noticed floaters when looking at the cloudy } \\
\text { sky. }\end{array}$ & 1 & 2 & 3 & 4 \\
\hline 3. & $\begin{array}{l}\text { Because of floaters, how much difficulty do you } \\
\text { have watching at a far distance in the bright } \\
\text { environment? }\end{array}$ & 1 & 2 & 3 & 4 \\
\hline 4. & $\begin{array}{l}\text { Because of floaters, how much difficulty do you } \\
\text { have watching at a far distance in the dim } \\
\text { environment? }\end{array}$ & 1 & 2 & 3 & 4 \\
\hline 5. & $\begin{array}{l}\text { Because of floaters, how much difficulty do you } \\
\text { have reading newspaper or books in the daily } \\
\text { life? }\end{array}$ & 1 & 2 & 3 & 4 \\
\hline 6. & $\begin{array}{l}\text { Because of floaters, how much difficulty do you } \\
\text { have working at a near distance in the daily life? }\end{array}$ & 1 & 2 & 3 & 4 \\
\hline 7. & $\begin{array}{l}\text { Because of floaters, how much difficulty do you } \\
\text { have finding something in the crowded place? }\end{array}$ & 1 & 2 & 3 & 4 \\
\hline 8. & $\begin{array}{l}\text { Because of floaters, how much difficulty do you } \\
\text { have driving? }\end{array}$ & 1 & 2 & 3 & 4 \\
\hline 9. & $\begin{array}{l}\text { Because of floaters, how much difficulty do you } \\
\text { have noticing objects off to the side while you } \\
\text { are walking alone? }\end{array}$ & 1 & 2 & 3 & 4 \\
\hline 10. & $\begin{array}{l}\text { Because of floaters, how much difficulty do you } \\
\text { have seeing how people react to things you say? }\end{array}$ & 1 & 2 & 3 & 4 \\
\hline 11. & $\begin{array}{l}\text { How much do floaters influence your mood } \\
\text { when you are working or studying? }\end{array}$ & 1 & 2 & 3 & 4 \\
\hline 12. & $\begin{array}{l}\text { How much do floaters influence your mood } \\
\text { when you are using computer? }\end{array}$ & 1 & 2 & 3 & 4 \\
\hline 13. & $\begin{array}{l}\text { How much do floaters influence your mood } \\
\text { when you are watching } T V / \text { movies? }\end{array}$ & 1 & 2 & 3 & 4 \\
\hline
\end{tabular}

Fig. 1 Vitreous Floaters Symptom Questionnaire-13 items 
aberration (HOA) and area ratio of modulation transfer function (MTFa). All values were obtained at the 4-mm zone of pupil. Patients underwent meticulous fundus examination to find evidence of floaters (e.g., Weiss ring, collagen aggregates) or any indication of peripheral retinal breaks/lattice degeneration. The eye with more severe symptoms was selected if floaters were seen in both eyes. Participants with floaters were divided into two groups: complete PVD and non PVD [21, 22]. A PVD was considered complete by biomicroscopy under mydriasis if a Weiss ring was visualized or by B-scan ultrasound imaging if the posterior hyaloid was detached at the optic nerve head [23]. The patients with other floaters were included in the non-PVD group.

\section{Inclusion and Exclusion Criteria}

Inclusion criteria were: primary symptomatic floaters found on pupil-dilated vitreous and fundus examination; at least 3 months' duration of floater symptoms [24]; floaters located at least $3 \mathrm{~mm}$ and $5 \mathrm{~mm}$ from the retina and posterior lens capsule of the crystalline lens, respectively [17], as assessed using an B-scan ultrasound or reference to lens thickness on oblique illumination by slit lamp in order to improve safety; ability to undertake YAG laser procedure; acceptance of related risks. Patients with evidence of peripheral retinal breaks/lattice degeneration or with a history of glaucoma, severe cataract, vitreous hemorrhage, retinal holes and/or macular disease were excluded from the study.

\section{Vitreous Floaters Symptoms Questionnaire}

We designed the Vitreous Floaters Symptoms Questionnaire (VFSQ-13) to assess symptoms related to vitreous floaters based on six parts of visual quality (distance activities, near activities, driving, social functioning, peripheral vision and mental health) to determine whether the floaters were bothersome. The questionnaire included 13 items to measure patients' subjective responses, highlighting the impact on visual disability and visual symptoms on daily function of the individual (Fig. 1). Questions 1 to 4 represent the influence of floaters on distance activities, questions 5 to 7 represent the influence of floaters on the near activities, question 8 represents the influence of floaters on driving, question 9 represents the influence of floaters on peripheral vision, question 10 represents the influence of floaters on social functioning, and questions 11 to 13 represent the influence of floaters on mental health. The composite score and scores in each evaluating part were calculated. Rasch analysis was used to investigate the validity of VFSQ-13 by comparing its psychometric properties against those of the validated National Eye Institute 25-Item Visual Function Questionnaire (NEI VFQ-25) [25]. The VFSQ-13 was administered at initial visit and at 6 months after treatment. During the face-to-face interviews, the research assistant helped to explain the questions if patients were unable to comprehend the questionnaire. Additionally, the patients were asked to quantify the improvement in vitreous floaters after YAG laser vitreolysis based on a five-level qualitative scale described by Delaney et al. [26]. The equivalent percentage of improvement was used: (1) worse: $<0 \%$; (2) the same: $0-30 \%$; (3) partial success: $30 \%$ to $50 \%$; (4) significant success: $>50 \%$; (5) complete success: $100 \%$.

\section{Treatment Procedure}

All the treatment procedures were performed by one experienced retinal specialist (T.Z.L.). The forms of floaters on examination were checked in accordance with the patients' complaint preoperatively. Following the measurement of IOP, the pupils were dilated with $0.5 \%$ tropicamide and $0.5 \%$ phenylephrine. One drop of $0.4 \%$ benoxinate hydrochloride (Santen Pharmaceutical Co., Ltd., Japan) was also administered, and a Volk Singh Mid vitreous lens was placed on the eye with gel (Dikeluo ${ }^{\circledR}$ Ofloxacin Eye Ointment, Shenyang Sinqi Pharmaceutical Co., Ltd., China). YAG laser vitreolysis was performed using the Ultra Q Reflex laser (Ellex Medical Lasers Ltd., Adelaide, Australia) with a maximum energy per pulse of $9 \mathrm{~mJ}$. Initially, the energy was set at $5 \mathrm{~mJ}$ and gradually 
increased to an appropriate level when the creation of gas bubbles could be observed. The number of laser shots used per eye was calculated. IOP was measured again at $30 \mathrm{~min}$ after treatment. The complications of treatment procedure were recorded too. During the 6-month follow-up period, all patients received YAG laser vitreolysis only once. After 6 months, rescue therapy with repeated YAG laser vitreolysis was possible, but the results were excluded from statistical analysis.

Post-treatment data were collected at 1 month, 3 months and 6 months. BCVA, IOP and pupil-dilated fundus examinations were examined at every follow-up time. The questionnaire survey, objective visual quality measures and SLO imaging (Fig. 2) were done again at 6-month follow-up. The area of floaters was manually delineated by an experienced retinal specialist (T.T.L.) on SLO photographs and automatically calculated by Optos' own software at baseline and month 6 . The areas of floaters were added together if multiple floaters existed. The area of floaters was also graded using a five-level qualitative scale $[17,26]$.

\section{Statistical Analysis}

Continuous variables were displayed as mean and standard deviation (SD), and categorical variables were displayed as percentage. Continuous variables were compared using the $t$ test, whereas chi-square test or Fisher exact test was used for the comparison of categorical variables between the groups. A paired $t$-test or McNemar nonparametric test was used to compare preand postoperative parameters. Rasch analysis was used to investigate the validity of VFSQ-13 scores for subjective floaters. Mean-square statistic values between 0.70 and 1.30 were classified as productive for the measurement. An estimation of the effective rate was described as $95 \%$ confidence interval (CI). Depending on one-tailed paired $t$-test, alpha level was set at 0.05; the power of the statistic was set at 95\% for this study. All statistical analyses were performed with SPSS, software version 27.0 (SPSS Inc., Chicago, IL, USA).

\section{RESULTS}

The mean age of all participants was $56.80 \pm 10.82$ (range 24-76) years old, with a distinct female predominance (72.55\%). Twenty-nine out of $51(56.86 \%)$ eyes with floaters were non-PVD type, and the rest were PVD type. The mean laser shots were $221.22 \pm 117.15$, and the mean energy of laser was $7.09 \pm 1.25 \mathrm{~mJ}$ per pulse. Though fewer laser shots were used in the non-PVD group compared to the PVD group, there was no statistically significant difference between the two groups $(202.06 \pm 128.69$ vs. $246.47 \pm 98.07$, $p=0.094)$ (Table 1$)$.

In total, 36 of $51 \quad(70.59 \% ; \quad 95 \%$ CI 58.10-83.10) patients reported their symptoms as significant or complete improvement (50-100\%) after treatment, $72.73 \%$ and $68.97 \%$ $(p=0.344)$ in the PVD group and non-PVD group, respectively (Fig. 3). Seventeen of 29 $(58.62 \%)$ eyes with non-PVD floaters and 18 of $22(81.82 \%)$ eyes of PVD type could be noticed on SLO images $(p=0.020)$. Except for the eyes with invisible floaters on SLO images, the significant or complete resolution of floater measurement in the PVD group and non-PVD group were both $100 \%$.

After YAG laser vitreolysis, the mean MTFa, internal SA and internal HOA improved significantly in all eyes $(26.19 \pm 14.73$ vs. $29.19 \pm 17.98, \quad p=0.013 ; \quad 0.05 \pm 0.05 \quad$ vs. $0.04 \pm 0.04, p=0.031$ and $0.23 \pm 0.22$ vs. $0.16 \pm 0.07, p=0.044$; respectively) (Table 2; Fig. 4). There was no significant difference in the comparison of the change in the objective visual quality measures after YAG laser vitreolysis between the PVD group and the non-PVD group (all $p>0.05$ ) (Table 3).

The mean-square fit statistics (Infits MNSQ and Outfit MNSQ) of the VFSQ-13 in the Rasch analysis are presented in Table 4 . The items "Near activities", "Peripheral activities" and "Driving" had at least one fit statistic out of the range of $0.70-1.30$ logit, which indicated that these items were misfitted for the VFQ-25 for the cohort under investigation in this study. The principal component analyses of the standardized residuals from the Rasch analyses of 


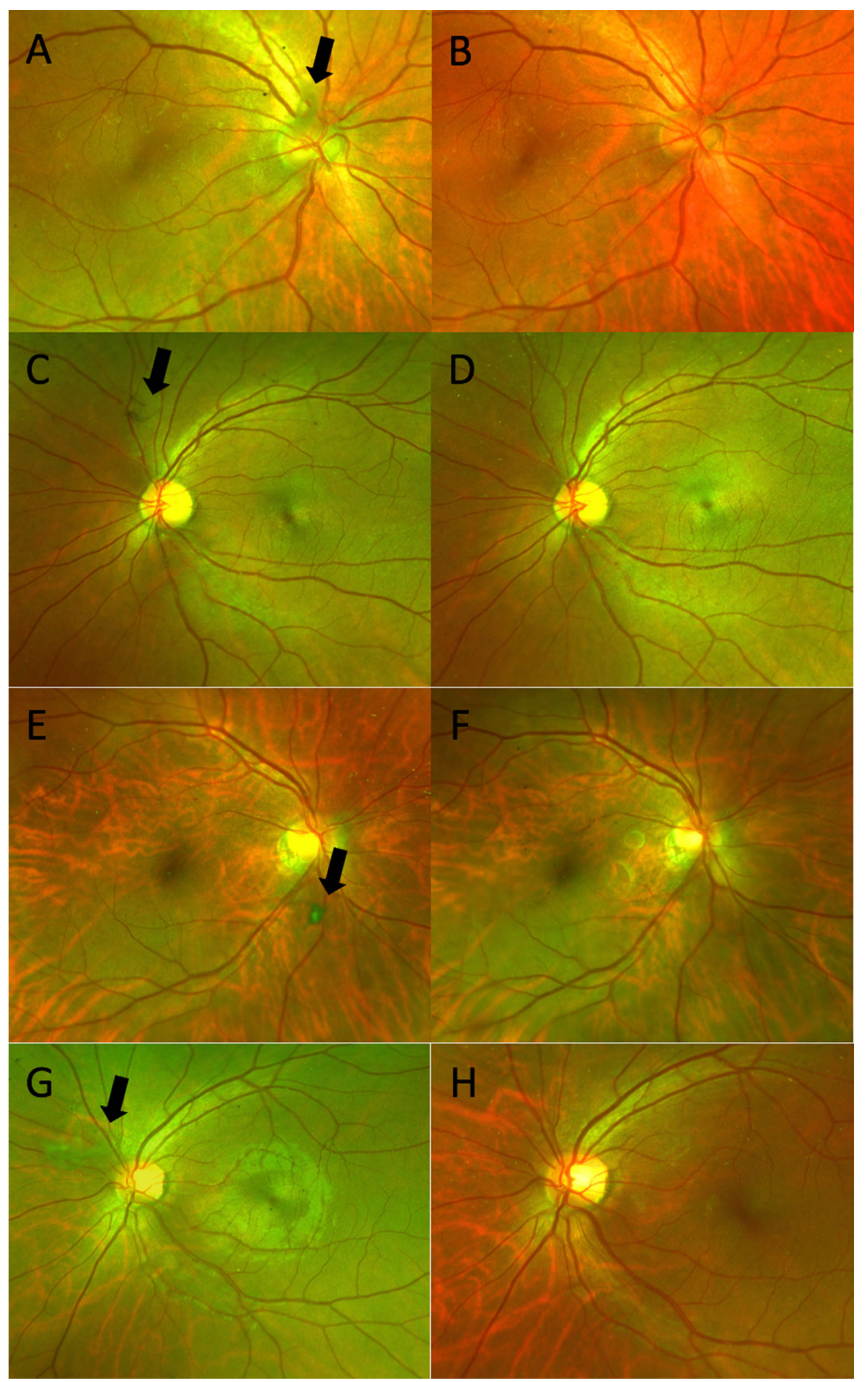


4Fig. 2 SLO images of vitreous opacities (black arrows) before and after YAG laser vitreolysis. A visible Weiss ring in front of the ON (complete PVD type) was noted in the right eye of a 60-year-old female (A); the Weiss ring vanished following YAG laser vitreolysis $(7 \mathrm{~mJ} /$ pulse, 621 shots) (B). A lamellar vitreous opacity superior to the $\mathrm{ON}$ (non-PVD type) in the left eye of a 42-year-old female (C); the vitreous opacity resolved after YAG laser vitreolysis $(6 \mathrm{~mJ} /$ pulse, 210 shots) (D). A punctual vitreous opacity noted inferior to the (complete PVD type) in the right eye of a 58-year-old female $(\mathbf{E})$; the vitreous opacity resolved following YAG laser vitreolysis $(6 \mathrm{~mJ} /$ pulse, 322 shots) (F). A cotton-like vitreous opacity noted nasal-superior to the ON (non-PVD type) in the left eye of a 39-year-old male $(\mathbf{G})$; the vitreous opacity resolved following YAG laser vitreolysis (9 mJ/pulse, 450 shots) $(\mathbf{H})$. ON optic nerve

VFSQ-13 gave an eigenvalue of the first principal component of 1.62, whereas for the VFQ-25, the eigenvalue of the first principal component had a value of 1.88 . Since both eigenvalues were $>1$, this indicated the unidimensionality feature of both questionnaires. Furthermore, the distribution of the Rasch residuals for VFSQ-13 and VFQ-25 had identical patterns, although the distribution for VFSQ-13 was slightly tighter around 0 (range -1.5 to 1.5 ) compared to that of VFQ-25 (range -2 to 1.5) (see Figure S1 in the electronic supplementary material for details). However, the analysis of the item's characteristic curves of VFSQ-13 and VFQ-25 suggested the following: using VFSQ-13, only three (respectively, four) ranges of the rating scales were enough to capture the underlaying latent trait for the items "Driving," "Social functioning," "Near activities" and "Peripheral vision" (respectively, "Mental health" and "Distance activities"), whereas using VFQ-25, only three (respectively, four) ranges of the rating scales were enough to capture the underlaying latent trait for the items "Social functioning" and "Peripheral vision" (respectively, "Driving," "Mental health," "Near activities" and "Distance activities"). Overall, the item characteristic curves of the VFSQ-13 provided a clearer separation of the ranges of the rating scales, which were enough to capture the underlaying latent trait. These analyses highlighted that the psychometric properties of the VFQ-25 were not superior to those of the VFSQ13 , at least in the clinical population considered in this study. However, the VFSQ-13 was significantly shorter than VFQ-25, which was more convenient for patient assessment and followup.

In the analysis of VFSQ-13, the composite score, distance activities, near activities, social functioning, peripheral vision and mental health had all improved significantly after YAG laser vitreolysis but not driving $(p=0.162)$ (Fig. 5). In the comparison of the change of VFSQ-13 scores after YAG laser vitreolysis between the PVD group and the non-PVD group, no significant difference was found (all $p>0.05$ ) (Table 3).

Table 1 Demographic characteristics and surgical parameters of patients in two groups

\begin{tabular}{llll}
\hline Variables & Non-Weiss $(\boldsymbol{n}=\mathbf{2 9})$ & Weiss $(\boldsymbol{n}=\mathbf{2 2})$ & $\boldsymbol{p}$ value \\
\hline Age, years & $55.55 \pm 13.24$ & $62.00 \pm 6.34$ & 0.174 \\
Female, $n$ (\%) & $21(72.41)$ & $16(72.73)$ & 0.194 \\
LogMAR BCVA & $0.10 \pm 0.13$ & $0.20 \pm 0.19$ & 0.215 \\
IOP (mmHg) & $17.31 \pm 2.39$ & $17.82 \pm 2.79$ & 0.244 \\
SE & $-1.14 \pm 2.90$ & $-2.63 \pm 5.25$ & 0.115 \\
Power of YAG laser & $7.05 \pm 1.25$ & $7.14 \pm 1.28$ & 0.407 \\
Number of shots & $202.06 \pm 128.69$ & $246.47 \pm 98.07$ & 0.094 \\
\hline
\end{tabular}

$B C V A$ best corrected visual acuity, $I O P$ intraocular pressure, $S E$ spherical equivalent, $Y A G$ yttrium aluminum garnet 


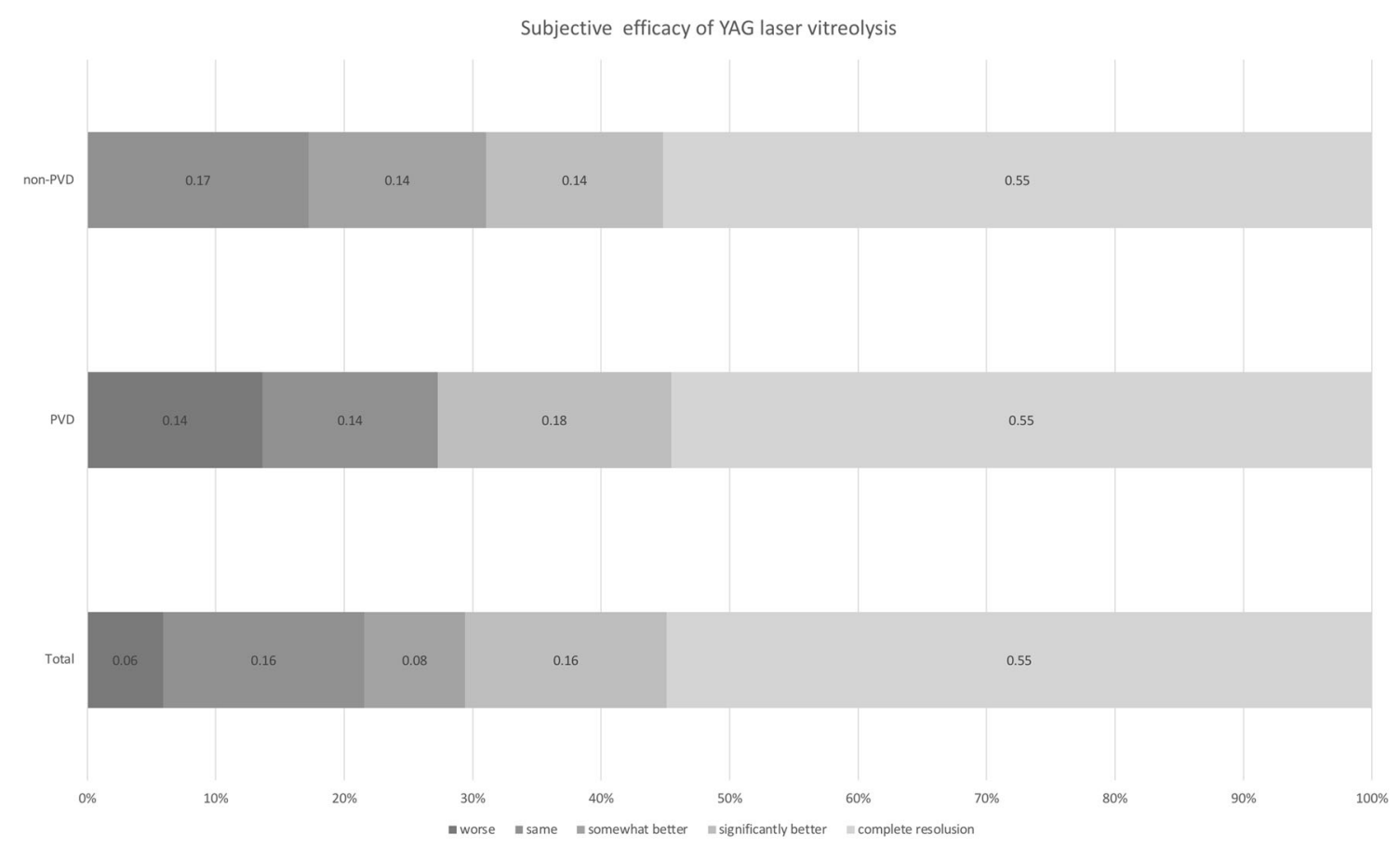

Fig. 3 Subjective efficiency of a five-level qualitative scale after YAG laser vitreolysis

Table 2 Objective visual quality measures before and after treatment in all eyes

\begin{tabular}{lccc}
\hline Variables & Pre-operation & Post-operation & $\boldsymbol{p}$ value \\
\hline SR & $0.03 \pm 0.02$ & $0.04 \pm 0.05$ & 0.090 \\
Internal SA & $0.05 \pm 0.05$ & $0.04 \pm 0.04$ & 0.031 \\
Internal CA & $0.08 \pm 0.08$ & $0.05 \pm 0.03$ & 0.071 \\
Internal HOA & $0.23 \pm 0.22$ & $0.16 \pm 0.07$ & 0.044 \\
MTF area ratio (\%) & $26.19 \pm 14.73$ & $29.19 \pm 17.98$ & 0.013 \\
\hline
\end{tabular}

$S R$ s Strehl ratio, $S A$ spherical aberration, $C A$ comatic aberration, $H O A$ high-order aberration, $M T F$ modulation transfer function

Previous studies have reported focal cataract, elevation of IOP, retinal hemorrhage or retinal detachment after YAG laser vitreolysis [27]. However, in this study, none of the patients experienced complications associated with YAG laser vitreolysis. Three patients (5.9\%) presented postoperative visual quality that was worse according to the questionnaire scores and complained of more tiny asteroid floaters or floaters remnants.

There were five eyes with high myopia (all $\mathrm{SE} \leq-10.00 \mathrm{D})$, four eyes in the PVD group and one eye in the non-PVD group. Three patients were satisfied with the treatment (50-100\% improvement). Two patients in the PVD group complained of no change in floaters after treatment.

\section{DISCUSSION}

In 1993, Tsai et al. [28] first reported the application of YAG laser $(5-10 \mathrm{~mJ})$ for treating symptomatic floaters and obtained satisfactory 


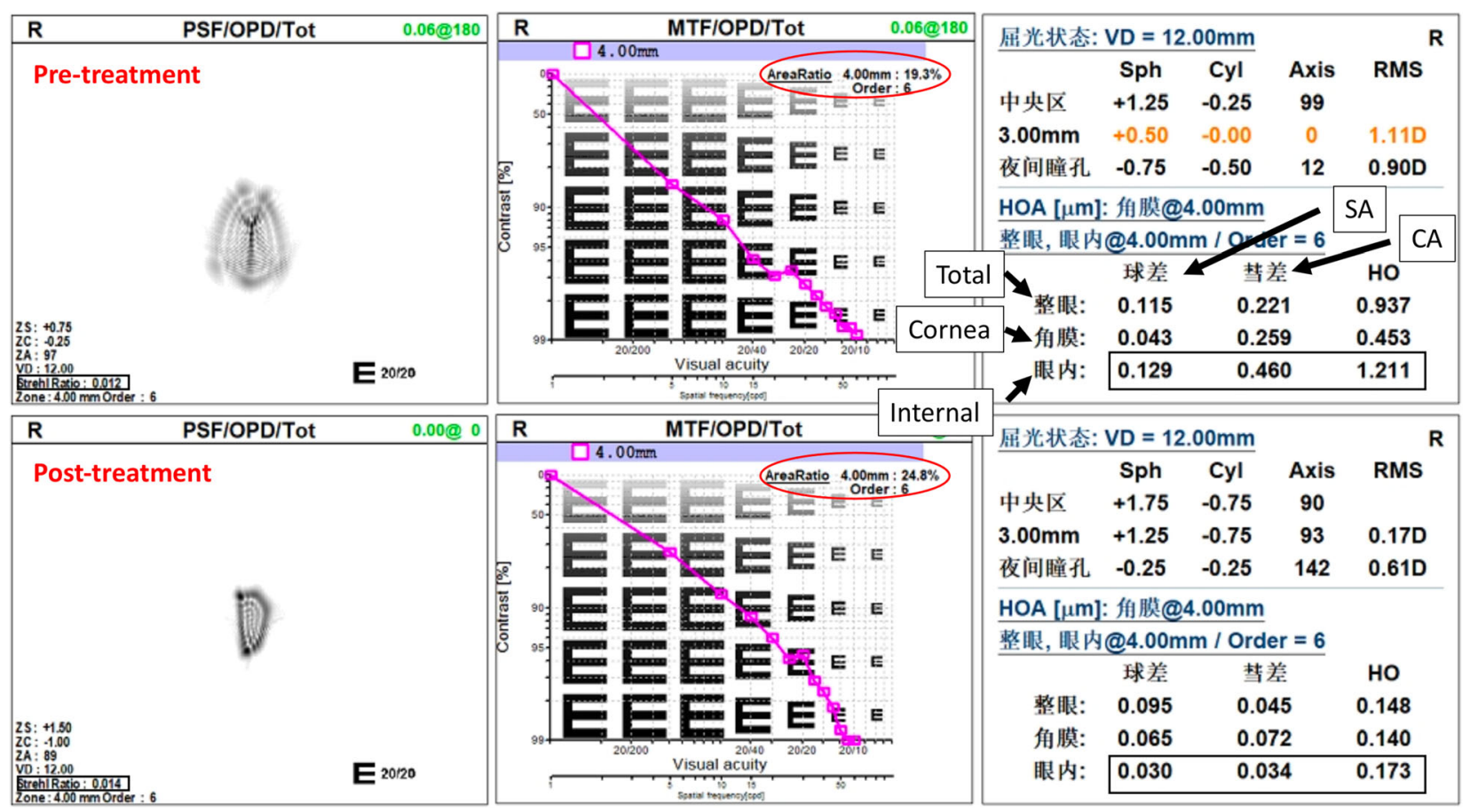

Fig. 4 Objective visual quality measures in the right eye of a 55-year-old female with non-PVD floaters before (top) and after (bottom) YAG laser vitreolysis. $S A$ spherical aberration, $C A$ comatic aberration, $H O$ high-order aberration

treatment results during 1-year follow-up. However, Delany et al. [26] found that $35.8 \%$ patients with symptomatic floaters had moderate resolution, and only $2.5 \%$ patients felt significant improvement after YAG laser treatment. However, the maximum laser energy used by Delany et al. was just $1.2 \mathrm{~mJ}$ and may not have been adequate to vaporize the floaters; therefore, the low energy of the laser might have been the reason for less satisfactory outcome [13]. In the present study, we used laser energy ranging from 5 to $9 \mathrm{~mJ}$, which is safe and potent enough to vaporize floaters. Overall, $70.59 \%$ patients reported their floater symptoms significantly or completely improved, and in the PVD type group of patients that improvement was in $72.73 \%$. The findings of the current study are in accordance with the recent studies reported by Shah et al. [17] and Ludwig et al. [18]. In their randomized clinical trials, $53 \%$ and $77 \%$ patients with symptomatic PVD felt significant and complete resolution after YAG laser vitreolysis with the energy from 3 to $7 \mathrm{~mJ}$ and 4 to $7.2 \mathrm{~mJ}$, respectively.
Primary symptomatic floaters are usually classified as PVD and non-PVD types, and the Weiss ring is the sign of complete PVD in clinic [24]. Age and myopia are the two main causes of floaters. While symptomatic floaters with a Weiss ring are the main type in the elderly, most floaters without a Weiss ring happen in young people and usually are associated with myopia. Five patients with high myopia were included in this study, and four eyes had a clear Weiss ring. We did a careful fundus examination to check peripheral unstable degeneration such as lattice degeneration vitreous retinal traction before the YAG laser vitreolysis. On further analysis, three of them were satisfied with the treatment with no complications such as elevation of IOP or retinal detachment during the follow-up period. In this study, the spherical equivalent was not significantly different between two groups $(-2.85 \pm 6.10$ vs. $-0.58 \pm 3.25, p=0.608$ ), and the age was also comparable $(58.67 \pm 6.23$ vs. $55.79 \pm 12.62$, $p=0.782$ ), so we could consider that age might play important roles in the formation of floaters in two types of floaters. Symptomatic floaters of 
Table 3 Change of VFSQ-13 scores and objective visual quality measures after YAG laser vitreolysis in two groups

\begin{tabular}{lccc}
\hline VFSQ-13 & Non-PVD $(\boldsymbol{n}=\mathbf{2 9})$ & PVD $(\boldsymbol{n}=\mathbf{2 2})$ & $\boldsymbol{p}$ value \\
\hline Distance activities & $10.80 \pm 12.53$ & $9.38 \pm 14.97$ & 0.370 \\
Near activities & $10.23 \pm 16.65$ & $3.33 \pm 10.61$ & 0.061 \\
Driving & $2.27 \pm 7.36$ & $1.25 \pm 15.12$ & 0.389 \\
Peripheral vision & $9.09 \pm 19.74$ & $5.00 \pm 10.26$ & 0.206 \\
Social functioning & $3.41 \pm 8.78$ & $7.50 \pm 14.28$ & 0.133 \\
Mental health & $8.71 \pm 15.53$ & $7.08 \pm 13.32$ & 0.359 \\
Composite score & $7.42 \pm 9.65$ & $5.59 \pm 9.16$ & 0.267 \\
Objective visual quality & & & 0.226 \\
SR & $0.01 \pm 0.40$ & $0.01 \pm 0.02$ & 0.242 \\
Internal SA & $0.01 \pm 0.02$ & $-0.02 \pm 0.04$ & 0.247 \\
Internal CA & $-0.01 \pm 0.03$ & $-0.03 \pm 0.11$ & 0.222 \\
Internal HOA & $-0.04 \pm 0.12$ & $-0.10 \pm 0.27$ & 0.212 \\
\hline MTF (area ratio, \%) & $4.12 \pm 8.52$ & $2.02 \pm 4.91$ & \\
\hline
\end{tabular}

$Y A G$ yttrium aluminum garnet, $P V D$ posterior vitreous detachment, $V F S Q$ vitreous floaters survey questionnaire, $S R s$ Strehl ratio, $S A$ spherical aberration, $C A$ comatic aberration, $H O A$ high-order aberration, $M T F$ modulation transfer function

the PVD type were usually selected for YAG laser treatment in the previous studies $[17,18,26]$. We used YAG laser vitreolysis treatment for both types of floaters in this study. We did not find any significant difference in efficacy between the two types of floaters on subjective and objective assessment.

OPD-Scan III can provide objective metrics to describe MTFa, SR, inter SA, inter CA and inter HOA. The MTFa value represents the area beneath the MTF metric, indicating its potential utility as a preclinical metric [28, 29]. The greater the MTFa value, the better the eye's optical quality is. The SR value corresponds to the maximum point-spread function central luminance compared to that in an ideal ocular system free of aberrations. The values range from 0 to 1 , where 1 indicates a perfect optical system [30]. In this study, the MTFa, internal SR, internal SA and internal HOA demonstrated statistically significant improvements after YAG laser vitreolysis. These results indicate objective visual quality measures can be used to assess the efficacy of YAG laser vitreolysis in patients with decreased visual quality due to floaters.

Color fundus photos $[17,19]$ or quantitative ultrasonography [32] for objective assessment of floaters was used in previous studies. We used SLO imaging to objectively assess floaters. The sensitivity was $81.82 \%$ on the PVD type and $58.62 \%$ on the non-PVD type. Song et al. [33] used SLO and optical coherence tomography to assess vitreous floaters in 196 eyes. Peripapillary vitreous opacity (PVO) was noticed in 122 eyes (62.2\%). They speculated PVO was found in SLO images usually after PVD initiation, and the Weiss ring is the advanced stage PVD. Fibrillar aggregation is a common cause in non-PVD floaters, which can cause sufficient interference with photon transmission to induce chronic and progressive floaters [34, 35]. These floaters are typically in the form of strands or small spots $[34,35]$. Sometimes it is hard for SLO to project the shadows of these floaters on the imaging since SLO imaging is an auxiliary tool for evaluating floaters. Additionally, many factors were correlated with the projecting 
Table 4 Infits and outfits MNSQ statistics of the VFSQ13 and VFQ-25 questionnaires

\begin{tabular}{lll}
\hline Items & Infits MNSQ & Outfits MNQS \\
\hline VFSQ-13 & & \\
Distance activities & 1.01 & 1.01 \\
Near activities & 0.85 & 0.81 \\
Driving & 0.82 & 1.15 \\
Peripheral vision & 0.77 & 0.99 \\
Social functioning & 1.04 & 1.3 \\
Mental health & 1.23 & 1.21 \\
VFQ-25 & & \\
Distance activities & 0.81 & 0.77 \\
Near activities & 0.65 & 0.71 \\
Driving & 1.67 & 2.06 \\
Peripheral vision & 0.79 & 0.6 \\
Social functioning & 0.74 & 1.16 \\
Mental health & 0.96 & 0.92 \\
\hline
\end{tabular}

shadows of floaters, such as the floater's size, density and the distance between the floaters and the retina [36].

Some studies reported that symptomatic floaters could affect reading, driving and mood in daily life $[10,12]$. Contrast sensitivity was decreased in patients with symptomatic floaters
$[27,37,38]$. Symptomatic floaters have also been reported to be associated with depression, anxiety and perceived stress [39]. In the analysis of VFSQ-13 in this study, the composite score, distance activities, near activities, social functioning, peripheral vision and mental health became significantly better after YAG laser vitreolysis, but there was not significant improvement in driving after treatment. These outcomes were in accordance with the NEIVFQ-25 scores in a randomized clinical trial [17]. Previous studies have also demonstrated that vitrectomy has a good effect on reducing the symptoms mentioned above $[10,12,31,37,38]$. YAG laser vitreolysis also showed promising outcomes in this study.

Whether YAG laser vitreolysis is ready for primary symptomatic floaters is still under debate [4, 13, 24, 32, 40]. Nguyen et al. [32] reported that YAG-treated eyes had 23\% less vitreous echodensity and found no changes in BCVA, CSF and NEI-VFQ-39 questionnaire scores compared with untreated control eyes with vitreous floaters. However, there was no documentation concerning the laser type, parameters and number of sessions. Though the history of YAG laser vitreolysis for floaters is nearly 30 years, there are still limited studies reporting the efficacy of this treatment. Lighting, energy delivery and active cooling cavity technology have all advanced significantly in recent years. That might allow us to perform laser vitreolysis treatment with better safety and efficacy. Some might question the YAG laser

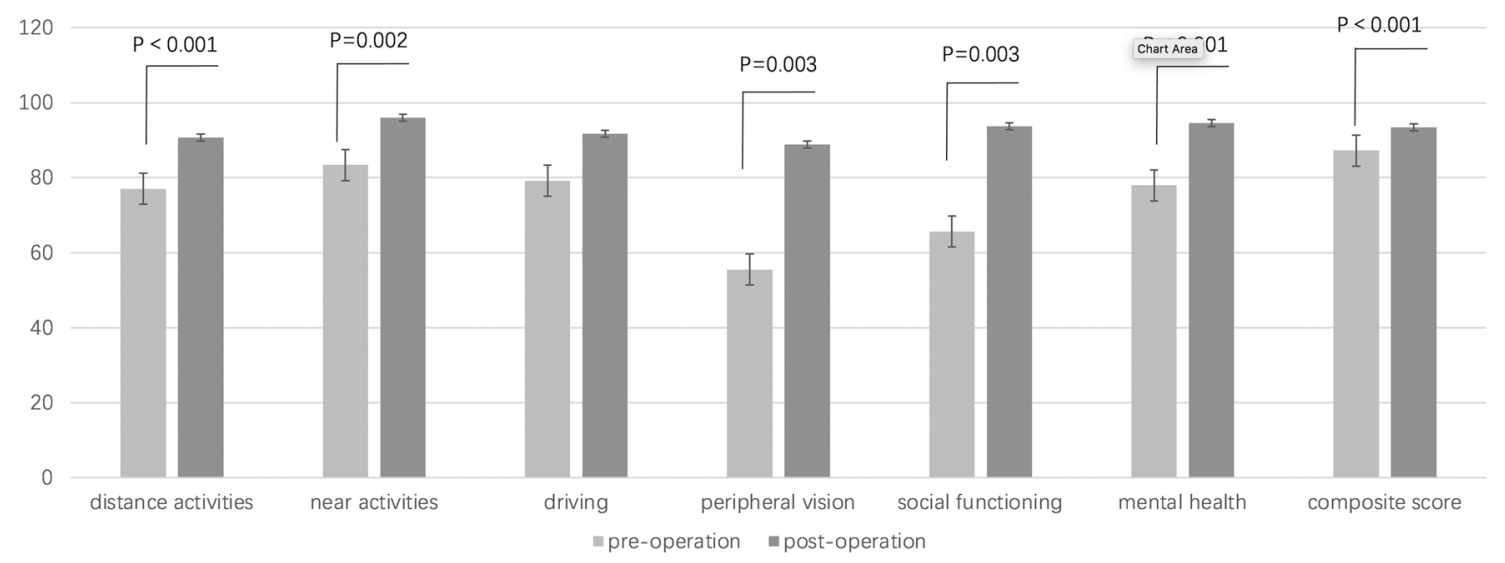

Fig. 5 VFSQ-13 scores before and after YAG laser vitreolysis in all eyes. VFSQ Vitreous Floaters Symptoms Questionnaire 
vitreolysis for non-PVD floaters. The multiple dot-like or cloudy diffuse condensations within the vitreous structure are more difficult to approach by laser [21]. Previous studies have revealed that the floaters closer to the retina make the symptoms more severe [36], so we mainly vaporized the more posterior floaters that could cause obvious symptoms in this study. Additionally, besides vaporizing the vitreous opacity or cutting the opacity into small pieces, the YAG laser vitreolysis can also be used to move floaters peripherally and/or anteriorly, resulting in decreased symptoms of floaters. The reasons mentioned above might be a plausible explanation for the good results of YAG laser vitreolysis in non-PVD floater participants in this study. Meanwhile, we did not find any significant changes in VFSQ-13 scores and the objective visual quality measures after YAG laser vitreolysis between the two groups in this study.

The complications of YAG laser vitreolysis for floaters, including focal cataract, elevation of IOP, retinal hemorrhage or retinal detachment, have been reported before [27]. We did not find any complication in the current study, but longer follow-up time is still needed to evaluate the safety of YAG laser vitreolysis in the future. Accurate assessment of floaters' position relative to the lens and retina is very important, Shah et al. [17] and Ludwig et al. [18] also did not report any complications associated with YAG laser vitreolysis on symptomatic floaters in their studies. In this study, few patients felt their subjective visual quality was worse and complained of tiny asteroid floaters created.

There are several limitations in the current study, including its small sample size, open design and short follow-up period as well as being a single center study and having no control group. We did not evaluate PVD progression on OCT either. We could not analyze the risk factors correlated with the poor outcomes of laser vitreolysis because of the small sample. However, to the best of our knowledge, this is the first study to analyze and compare the efficacy of YAG laser vitreolysis on floaters in complete PVD type and non-PVD type; additionally, this study used objective visual quality measures to evaluate the efficacy of YAG laser vitreolysis for symptomatic floaters.

\section{CONCLUSION}

In conclusion, the current study suggests that YAG laser vitreolysis for primary symptomatic floaters has the ability to improve subjective and objective short-term visual outcome. YAG laser vitreolysis might be a promising option for primary symptomatic floaters. The efficacy of YAG laser vitreolysis is comparable in floaters of the complete PVD and the non-PVD type.

\section{ACKNOWLEDGEMENTS}

Funding. This study, including the journal's Rapid Service Fees, was supported in part by the National Science Foundation of Liaoning Province, China (2020-MS-360). The funding organization had no role in the design or conduct of this research.

Authorship. All named authors meet the International Committee of Medical Journal Editors (ICMJE) criteria for authorship for this article, take responsibility for the integrity of the work as a whole, and have given their approval for this version to be published.

Author Contributions. The conception or design of the work (Tiezhu Lin, Lijun Shen); analysis and interpretation (Tiezhu Lin, Xinmei Zhang, Guangzheng Dai, Salissou Moutari); data collection and drafting the work (Tiezhu Lin, Tongtong Li, Emmanuel Eric Pazo, Salissou Moutari); critical revision of the article (Tiezhu Lin, Lijun Shen, Yannian Hui); final approval of the version (Tiezhu Lin, Lijun Shen).

Disclosures. Tiezhu Lin, Tongtong Li, Xinmei Zhang, Yannian Hui, Salissou Moutari, Emmanuel Eric Pazo, Guangzheng Dai and Lijun Shen all confirm that they do not have any conflicting interests to declare. 
Compliance with Ethics Guidelines. The study was approved by the He Eye Specialist Hospital of Medicine Institutional Review Board. The protocol adhered to the tenets of the Declaration of Helsinki and was compliant with HIPAA.

Data Availability. The data sets generated during and/or analyzed during the current study are available from the corresponding author on reasonable request.

Open Access. This article is licensed under a Creative Commons Attribution-NonCommercial 4.0 International License, which permits any non-commercial use, sharing, adaptation, distribution and reproduction in any medium or format, as long as you give appropriate credit to the original author(s) and the source, provide a link to the Creative Commons licence, and indicate if changes were made. The images or other third party material in this article are included in the article's Creative Commons licence, unless indicated otherwise in a credit line to the material. If material is not included in the article's Creative Commons licence and your intended use is not permitted by statutory regulation or exceeds the permitted use, you will need to obtain permission directly from the copyright holder. To view a copy of this licence, visit http://creativecommons.org/licenses/by$\mathrm{nc} / 4.0 /$.

\section{REFERENCES}

1. Webb BF, Webb JR, Schroeder MC, North CS. Prevalence of vitreous floaters in a community sample of smartphone users. Int J Ophthalmol. 2013;6:402-5.

2. Murakami K, Jalkh AE, Avila MP, Trempe CL, Schepens CL. Vitreous floaters. Ophthalmology. 1983;90:1271-6.

3. Milston R, Madigan MC, Sebag J. Vitreous floaters: etiology, diagnostics, and management. Surv Ophthalmol. 2016;61:211-7.

4. Broadhead GK, Hong T, Chang AA. To treat or not to treat: management options for symptomatic vitreous floaters. Asia Pac J Ophthalmol (Phila). 2020;9:96-103.

5. Schulz-Key S, Carlsson JO, Crafoord S. Long term follow-up of pars plana vitrectomy for vitreous floaters: complications, outcomes and patient satisfaction. Acta Ophthalmol. 2011;89:159-65.

6. Shah CP, Fine HF. Management of floaters. Ophthalmic Surg Lasers Imaging Retina. 2018;49: 388-91.

7. Zou H, Liu H, Xu X, Zhang X. The impact of persistent visually disabling vitreous floaters on health status utility values. Qual Life Res. 2013;22: 1507-14.

8. Wagle AM, Lim WY, Yap TP, Neelam K, Au Eong KG. Utility values associated with vitreous floaters. Am J Ophthalmol. 2011;152:60-5.

9. Wu RH, Jiang JH, Gu YF, Moonasar N, Lin Z. Pars plana vitrectomy relieves the depression in patients with symptomatic vitreous floaters. Int J Ophthalmol. 2020;13:412-6.

10. de Nie KF, Crama N, Tilanus MA, Klevering BJ, Boon CJ. Pars plana vitrectomy for disturbing primary vitreous floaters: clinical outcome and patient satisfaction. Graefes Arch Clin Exp Ophthalmol. 2013;251:1373-82.

11. Mason JO 3rd, Neimkin MG, Mason JO 4th, et al. Safety, efficacy, and quality of life following sutureless vitrectomy for symptomatic vitreous floaters. Retina. 2014;34:1055-61.

12. Lin Z, Zhang R, Liang QH, et al. Surgical outcomes of 27-gauge pars plana vitrectomy for symptomatic vitreous floaters. J Ophthalmol. 2017. https://doi. org/10.1155/2017/5496298.

13. Singh IP. Modern vitreolysis-YAG laser treatment now a real solution for the treatment of symptomatic floaters. Surv Ophthalmol. 2020;65:581-8.

14. Sommerville DN. Vitrectomy for vitreous floaters: analysis of the benefits and risks. Curr Opin Ophthalmol. 2015;26:173-6.

15. Appeltans A, Mura M, Bamonte G. Macular hole development after vitrectomy for floaters: a case report. Ophthalmol Ther. 2017;6:385-9.

16. Rubino SM, Parke DW 3rd, Lum F. Return to the operating room after vitrectomy for vitreous opacities: intelligent research in sight registry analysis. Ophthalmol Retina. 2021;5:4-8.

17. Shah CP, Heier JS. YAG laser vitreolysis vs sham YAG vitreolysis for symptomatic vitreous floaters: a 
randomized clinical trial. JAMA Ophthalmol. 2017;135:918-23.

18. Ludwig GD, Gemelli H, Nunes GM, Serracarbassa $\mathrm{PD}$, Zanotele M. Efficacy and safety of Nd:YAG laser vitreolysis for symptomatic vitreous floaters: a randomized controlled trial. Eur J Ophthalmol. 2020. https://doi.org/10.1177/1120672120968762.

19. Souza CE, Lima LH, Nascimento H, Zett C, Belfort R Jr. Objective assessment of YAG laser vitreolysis in patients with symptomatic vitreous floaters. Int J Retina Vitreous. 2020;6:1.

20. Su D, Shah CP, Hsu J. Laser vitreolysis for symptomatic floaters is not yet ready for widespread adoption. Surv Ophthalmol. 2020;65:589-91.

21. Brasse K, Schmitz-Valckenberg S, Jünemann A, Roider J, Hoerauf H. YAG laser vitreolysis for treatment of symptomatic vitreous opacities. Ophthalmologe. 2019;116:73-84.

22. Tassignon MJ, Ní Dhubhghaill S, Ruiz Hidalgo I, Rozema JJ. Subjective grading of subclinical vitreous floaters. Asia Pac J Ophthalmol (Phila). 2016;5: 104-9.

23. Wang MD, Truong C, Mammo Z, Hussnain SA, Chen RWS. Swept source optical coherence tomography compared to ultrasound and biomicroscopy for diagnosis of posterior vitreous detachment. Clin Ophthalmol. 2021;15:507-12.

24. Ivanova T, Jalil A, Antoniou Y, Bishop PN, VallejoGarcia JL, Patton N. Vitrectomy for primary symptomatic vitreous opacities: an evidence-based review. Eye (Lond). 2016;30:645-55.

25. Nickels S, Schuster AK, Singer S, Wild PS, LaubertReh D, Schulz A, et al. The National Eye Institute 25-Item Visual Function Questionnaire (NEI VFQ25)-reference data from the German populationbased Gutenberg Health Study (GHS). Health Qual Life Outcomes. 2017;15:156.

26. Delaney YM, Oyinloye A, Benjamin L. Nd:YAG vitreolysis and pars plana vitrectomy: surgical treatment for vitreous floaters. Eye (Lond). 2002;16: 21-6.

27. Hahn P, Schneider EW, Tabandeh H, Wong RW, Emerson GG. American Society of Retina Specialists Research and Safety in Therapeutics (ASRS ReST) Committee. Reported complications following laser vitreolysis. JAMA Ophthalmol. 2017;135:973-6.

28. Tsai WF, Chen YC, Su CY. Treatment of vitreous floaters with neodymium YAG laser. Br J Ophthalmol. 1993;77:485-8.
29. Alarcon A, Canovas C, Rosen R, Weeber H, Tsai L, Hileman K, et al. Preclinical metrics to predict through-focus visual acuity for pseudophakic patients. Biomed Opt Express. 2016;7:1877-88.

30. Vega F, Millán MS, Garzón N, Altemir I, Poyales F, Larrosa JM. Visual acuity of pseudophakic patients predicted from in-vitro measurements of intraocular lenses with different design. Biomed Opt Express. 2018;9:4893-906.

31. Saad A, Saab M, Gatinel D. Repeatability of measurements with a double-pass system. J Cataract Refract Surg. 2010;36:28-33.

32. Nguyen JH, Nguyen-Cuu J, Yu F, Yee KM, Mamou J, Silverman RH, et al. Assessment of Vitreous structure and visual function after neodymium: YttriumAluminum-garnet laser vitreolysis. Ophthalmology. 2019;126:1517-26.

33. Son G, Sohn J, Kong M. Acute symptomatic vitreous floaters assessed with ultra-wide field scanning laser ophthalmoscopy and spectral domain optical coherence tomography. Sci Rep. 2021;11(1):8930. https://doi.org/10.1038/s41598-021-88371-9.

34. Sendrowski DP, Bronstein MA. Current treatment for vitreous floaters. Optometry. 2010;81:157-61.

35. Sebag J. Floaters and the quality of life. Am J Ophthalmol. 2011;152:3-4.e1.

36. Serpetopoulos CN, Korakitis RA. An optical explanation of the entoptic phenomenon of "clouds" in posterior vitreous detachment. Ophthalmic Physiol Opt. 1998;18:446-51.

37. Garcia GA, Khoshnevis M, Yee KMP, Nguyen-Cuu J, Nguyen JH, Sebag J. Degradation of contrast sensitivity function following posterior vitreous detachment. Am J Ophthalmol. 2016;172:7-12.

38. Sebag J, Yee KM, Wa CA, Huang LC, Sadun AA. Vitrectomy for floaters: prospective efficacy analyses and retrospective safety profile. Retina. 2014;34: 1062-8.

39. Kim YK, Moon SY, Yim KM, Seong SJ, Hwang JY, Park SP. Psychological distress in patients with symptomatic vitreous floaters. J Ophthalmol. 2017. https://doi.org/10.1155/2017/3191576.

40. Katsanos A, Tsaldari N, Gorgoli K, Lalos F, Stefaniotou M, Asproudis I. Safety and efficacy of Nd:YAG Laser vitreolysis for the treatment of vitreous floaters: an overview. Adv Ther. 2020;37:1319-27. 